\title{
Comparison of three processes for parenteral nanoemulsion production: ultrasounds, microfluidizer and premix membrane emulsification
}

\author{
Océane Alliod, Eyad Almouazen, Georgio Nemer, Hatem Fessi, Catherine Charcosset* \\ Univ Lyon, Université Claude Bernard Lyon 1, CNRS, LAGEP UMR 5007, 43 boulevard du 11 novembre 1918, F-69100, \\ VILLEURBANNE, France
}

\begin{abstract}
Nanoemulsions are of great interest for pharmaceutical applications, including parenteral dosage forms. However, their production is still limited and requires more efficient and adaptive technologies. The more common systems are high-shear homogenization like microfludizers (MF) at industrial scale and ultrasounds at research scale, both based on high energy limiting their application for sensitive drugs. Recently, a process based on premix membrane emulsification (PME) was developed to produce nanoemulsions. These three processes have been compared for the production of a model parenteral nanoemulsion containing all-transretinoic acid, a thermolabile molecule which is used in the treatment of acute promyelocytic leukemia in a parenteral form. Droplet size and active integrity were studied because of their major interest for efficacy and safety assessment. Regarding droplet size, PME produced monodispersed droplets of $335 \mathrm{~nm}$ compared to the other processes which produced nanoemulsions of around $150 \mathrm{~nm}$ but with the presence of micron size droplets detected by laser diffraction and optical microscopy. No real difference between the three processes was observed on active degradation during emulsifcation. However, regarding stability, especially at $40^{\circ} \mathrm{C}$ nanoemulsions obtained with the microfluidizer showed a greater molecule degradation and unstable nanoemulsion with a 4 times droplet size increase under stress conditions.
\end{abstract}

Keywords: Parenteral Nanoemulsion, Premix membrane emulsification, atRA, Microfludizer, Ultrasounds

\section{Introduction}

Nanoemulsions are dispersed systems of droplets with nanometric diameter $(<500 \mathrm{~nm})$ which are used in several pharmaceutical dosage forms and cosmetic formulations. The small droplet size enhances emulsion kinetic stability, allows to solubilize and protect hydrophobic drug molecules and contributes to drug bioavailability enhancement. Their versatility, biocompatibility and biodegradability make these systems valuable

Abbreviations: atRA, all-trans-retinoic acid; DLS, Dynamic light scattering; DME, Direct membrane emulsification; FDA, Food and drug administration; HLB Hydrophilic and Lipophilic balance; HPLC High pressure liquid chromatography; LD, Laser diffraction; O/W, oil-in-water; MCT, Medium chain triglycerides; MF, Microfluidizer; PDI, Polydispersity index; PME, Premix membrane emulsification; SLN, Solid lipid nanoparticles SPG, Shirasu Porous Glass; ; US, Ultrasounds;

* Corresponding author. Address: Univ Lyon, Université Claude Bernard Lyon 1, CNRS, LAGEP UMR 5007,43 boulevard du 11 novembre 1918, F-69100, VILLEURBANNE, France. Tel.: +33472431834

Email address: catherine.charcosset@univ-lyon1.fr (Catherine Charcosset) 
pharmaceutical asset in different marketed dosage forms for oral, nasal, parenteral, dermal, transdermal, ocular and pulmonary administration routes [1, 2, 3].

Nanoemulsions are the unique choice for intravenous emulsion-based formulations which require specific and strict criteria including controlled droplet sizes (less than 1 or $2 \mu \mathrm{m}$ ) [4, restricted composition, physicochemical and biological stability and sterilized requirement. Parenteral nanoemulsions have been presented in numerous studies [5, 6, 7, 8, and were included in several clinical trials such as treatment of leukemia [9] and diabetic dyslipidemia [10]. Parenteral nanoemulsions are interesting formulations for the delivery of many drugs [4. They can avoid the use of conventional co-solvent systems and the associated undesirable effects caused by precipitation of the drug at the injection site, as well as protein binding and hydrolytic degradation of drugs. Another advantage of parenteral emulsions is their potential to achieve a sustained release and to target concerned tissue [7].

Manufacturing of nanoemulsions is usualy classified into low and high energy emulsification methods. Lowenergy emulsification methods are based on physico-chemical principles such as phase inversion temperature, phase inversion composition or nanoprecipitation [11]. However, the specific composition requirement inherent in these methods gives high energy methods an advantage. Indeed, high energy processes are suitable for a larger range of formulations as nanoemulsions are generated using mechanical devices with intensive disruptive forces that breakup the oil and water phases [12. Among these high energy methods, the most used are high pressure homogenizers, microfluidizers (MF) and ultrasounds (US). The two first techniques are based on similar technologies, a high pressure flux in a microchannel creating high shear stress with cavitation and impact. The main difference is that MF presents an interaction chamber of fixed geometry whereas in traditional high pressure homogenizers the valve moves to create the pressure. MF and high pressure homogenizers [13] require high energy input (pressure applied up to around 2000 bars). Unfortunately, only $0.1 \%$ of the energy input is actually used for emulsification, while the remaining energy (99.9\%) is dissipated as heat [14. Moreover, monodispersed droplets are obtained only after several cycles, as all droplets do not undergo the same shear stress depending on their position in the interaction chamber. US is based on cavitation mechanism and requires also high energy input. This process can generate nanoemulsions with very small droplet size, but usually broad size distributions are obtained and is limited to laboratory scale. The drawback of these technologies is their energy consumption but also the additional cost for scaling up, which is known as one of the biggest challenges for nanoemulsions production in the pharamaceutical industry 15]. Moreover, high thermal energy produced during emulsification limits their application for thermolabile drugs.

More recently, membrane emulsification has gained significant attention because of the low energy required leading to low shear stress and temperature increase and its good scalability. Membranes can be used either to generate an emulsion, the process is then called direct membrane emulsification or to modify it and is then called premix membrane emulsification (PME). In direct membrane emulsification, a dispersed phase is injected through membrane pores in a continuous phase. In PME, a coarse emulsion called premix is injected 
directly through the microporous membrane in order to form smaller droplets. Advantages of PME over DME are that the flowrate of the product emulsion is generally much higher, higher droplet concentrations are obtained and the mean droplet sizes are smaller [16, 17. For the production of nanoemulsions, PME is of great interest. Bunjes et al. prepared nanoemulsions by PME with droplet sizes lower or around $200 \mathrm{~nm}$ with a narrow size distribution [18, 19, 20]). This result was explained by the high pore tortuosity and thickness of the Shirasu Porous Glass (SPG) membranes which are the most commonly used membranes for emulsification. Using these SPG membranes and PME, Bunjes and Joseph produced a few milliliters of nanoemulsion [18, 19, 21]. The production of nanoemulsions by membrane emulsification remains a challenging undertaking 18] especially for large volumes at high flowrates. Hitherto, this process has been used to homogenize small amounts of emulsion, but a recent publication by Alliod et al. 22] proposed a novel approach which allowed the homogenization of $500 \mathrm{~mL}$ of coarse emulsion into a nanoemulsion by running it through membranes with average pore sizes at a minimum of $0.2 \mu \mathrm{m}$ whilst keeping pressure under 60 bars. Thus, PME can be used to create nanoemulsions that carry sensitive active pharmaceutical ingredients prone to isomerization or degradation. Also, this process presents additional industrial interest because it can work in a continuous way. Moreover, SPG membranes can be sterilized to ensure aseptic production for injectable nanoemulsions.

The aim of this study is to evaluate the potential of these three different processes on production of nanoemulsions within the specific requirements of parenteral formulation. The first process, MF, is a commercially and industrially available process. The second, US is a process used mostly at laboratory scale for the production of nanoemulsions. The last process, PME, has been used for many years for the preparation of emulsions with micron-sized droplets, but has been investigated only recently for the production of emulsions with droplets size below several microns. These three processes have never been investigated in the same study, however a study compared a traditionnal membrane process (micron size) and a microfludizer for emulsion production [23] and several compared ultrasounds and microfludizer for nanoemulsion production

65 [24, 25]. The first study showed interesting results for both processes but no size under one micron were reached with the membrane process 23 . Concerning comparison of US and MF, similar results in size were often obtained.

In order to evaluate the effect of each process on possible active degradation, a model active was chosen, all-trans-retinoic acid (atRA). This active has a great potential for injection but is very light and temperature sensitive. This active form of vitamin A, atRA, has been marketed for oral and topical administrations. Its therapeutic potential is thus far limited to the treatment of acne [26] and other superficial skin ailments and to the treatment of acute promyelocytic leukemia [27, 28, among other cancer types [29. Modern research posits that atRA influences tumor progression by affecting cancer cell proliferation rates and their state of differentiation [30]. Numerous research efforts were dedicated to the development of parenterally administrable forms in order to overcome the limitations of the existing prominent cancer-treating oral forms such as variable atRA bioavailability among patients and decrease its plasmatic level after long-term treatment [26]. Therefore, it has been the subject of thorough investigation to propose adaptable parenteral 
forms using cyclodextrins [31, liposomes [32, or lipid core nanocapsules [33, 34, 35. To our knowledge, no atRA-loaded nanoemulsion for parenteral administration has been developed.

The objective of this study is to compare the three processes for the production of atRA parenteral nanoemulsions regarding droplet size and drug stability. Firstly, the emulsion composition was selected after HLB (hydrophilic and lipophilic balance) determination, solubility and osmometry measurements. Then, nanoemulsions production was optimized regarding droplet size and dispersity. For that pressure and cycle number were investigated for MF, number of cycles coupled with pore size for PME and intensity and process-

85 ing time for US. Following this optimization, the more interesting conditions for each process were selected and the active preservation was determined over 3 months with four storage conditions, ie: dark conditions temperature of $4^{\circ} \mathrm{C}$, ambient temperature and $40^{\circ} \mathrm{C}$ and in light conditions at ambient temperature.

\section{Experimental Section}

\subsection{Materials}

AtRA, 13-cis-retinoic acid, 9-cis-retinoic acid, Tween 20 (Polysorbate 20), Span 80 (Polysorbate 80) were purchased from Sigma Aldrich (France). Derquim+ was purchased from Derquim (Spain), Labrafac wl1349 (MCT oil) was purchased from Gattefossé (France). Glycerol was purchased from Carl Roth (France). Ultrapure water was obtained using a Millipore (France) Synergy Unit system.

\subsection{Preparation of the premix}

In order to determine the final quantity of atRA to be added to the emulsion to ensure no-crystallization after manufacturing, the solubility in MCT was determined. Tween 20 and Span 80 were chosen because both emulsifiers are FDA approved for intravenous administration and are relatively innocuous in low quantities. Moreover, to ensure optimal stability of the nanoemulsion, the emulsifier mix was added at a mass percentage of $5 \%$ 22]. Finally, the osmolarity was adjusted by adding glycerol and was measured using an OSMOMAT 030 cryoscopic osmometer.

Preparations were all performed at room temperature. Both phases were first prepared separately. The oil phase was prepared by adding $10 \%$ MCT, $2.7 \%$ Span 80 and $0.2 \%$ atRA and stirring magnetically at 600 rpm until a homogeneous consistency was obtained. In the aqueous phase, $1.88 \%$ glycerol and $2.3 \%$ Tween 20 were dissolved in water. Once a homogeneous consistency was obtained for the aqueous phase, the oil phase was poured while magnetic stirring was set at $600 \mathrm{rpm}$. The mixture was stirred until a homogeneous and consistent white color was obtained. During all the process, exposition to day light was avoided.

\subsection{Production of nanoemulsions}

\subsection{1. $P M E$}

The experimental set-up and method used for the preparation of nanoemulsions by PME are adaptated from the approach detailed by Alliod et al. 22 (Figure 1). The set-up comprised a high pressure benchtop 
single cylinder pump BTSP 500-5 (Floxlab, Nanterre, France). The pump is made of high grade stainless steel and equipped with a pressure sensor (0.1 bar), two pneumatic valves for tank feeding and outlet delivery, a control panel and a storage tank of $500 \mathrm{~mL}$. Pressurization was obtained by way of an electric motor-driven piston. A maximum flowrate of $200 \mathrm{~mL} / \mathrm{min}$ can be obtained with this pump. The membrane module was connected to the pump with high pressure fittings (Swagelock, France).

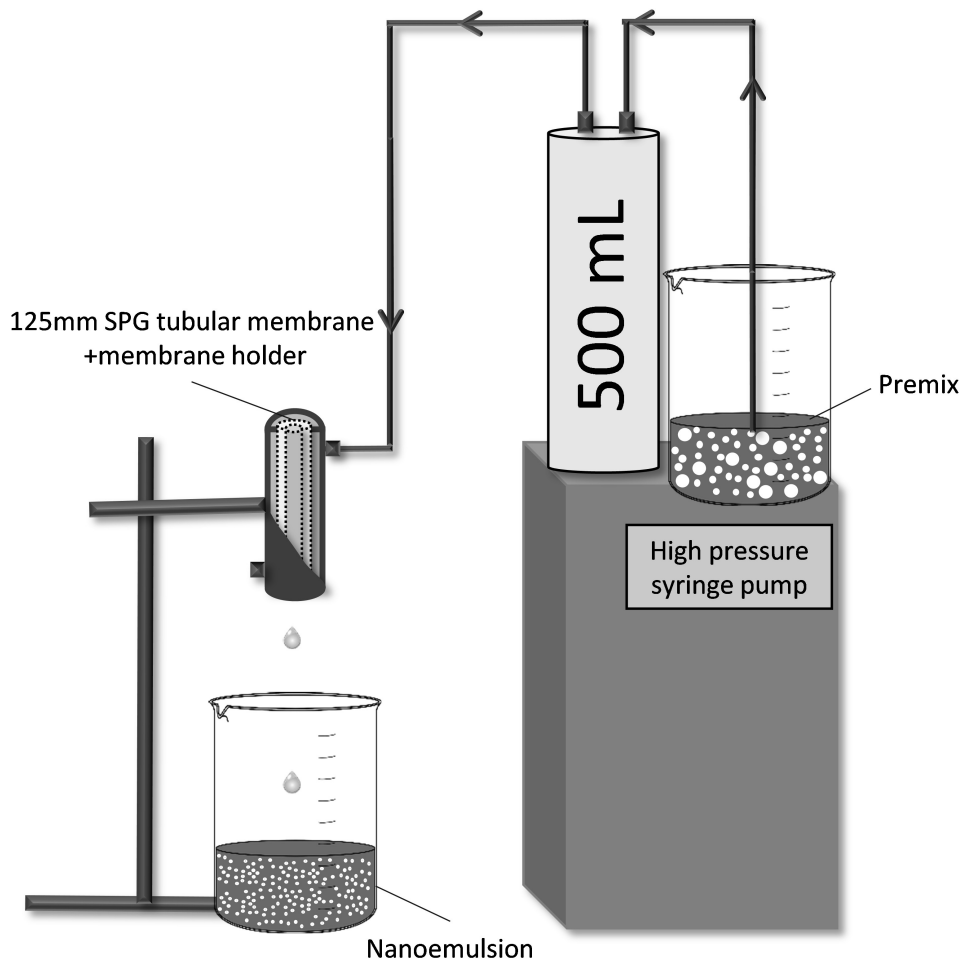

Figure 1: Experimental set-up of the high syringe pump with membrane holder and SPG membrane

Hydrophilic SPG membranes were provided by SPG Technology Co. Ltd (Miyazaki, Japan). These membranes are of a tubular design with an inner diameter of $8.5 \mathrm{~mm}$ and a uniform thickness of $0.8 \mathrm{~mm}$. $20 \mathrm{~mm}$ membranes were used throughout the experimentation. Membranes with mean pore size of 0.2 , $0.3,0.4,0.5 \mu \mathrm{m}$ were investigated and their mean pore size data was provided by the manufacturer. The membrane module used was an external pressure microkit module for membranes with a length of $20 \mathrm{~mm}$ (SPG Technology). The cleaning procedure consisted in three injections through the membrane of $500 \mathrm{~mL}$ of a $1 \%$ Derquim + solution [36] at $70^{\circ} \mathrm{C}$ and $200 \mathrm{~mL} / \mathrm{min}$, and then three injections of $500 \mathrm{~mL}$ of pure water at room temperature and $200 \mathrm{~mL} / \mathrm{min}$. The membrane resistance to water was recovered after this treatment.

${ }_{125}$ To produce nanoemulsions, the premix was placed in the feed tank and pumped in the syringe pump. First $20 \mathrm{~mL}$ premix was injected in order to remove air from the experimental set-up and fill it with premix. Most of the experiments were then carried out with volumes of injection from 40 to $200 \mathrm{~mL}$ to perform all cycles 
with sufficient material. The transmembrane pressure never exceeded 60 bars. The nanoemulsion produced flew from the membrane tube under gravity and was collected in a beaker placed beneath the module.

The membrane used for production at each cycle was the following: Cycle $1: 0.5 \mu \mathrm{m}$ pore size; Cycle 2 : $0.4 \mu \mathrm{m}$ pore size; Cycle 3: $0.3 \mu \mathrm{m}$ pore size; Cycle $4: 0.2 \mu \mathrm{m}$ pore size. After each cycle the emulsion was collected and analyzed. All emulsions were investigated in a stability study.

\subsection{2. $M F$}

An LM20 series Microfluidizer processor (Microfluidics, Massachussets, USA) was used. Its reservoir capacity is $300 \mathrm{~mL}$ and it can be operated at pressures up to 2068 bars.

The effects of several parameters were investigated: pressure values from 500 to 2000 bars; number of cycles : 1, 2, 3, 4, and 5 cycles. After each cycle, the emulsion was collected and analyzed. For the stability study, the preparations investigated were obtained after cycle 1, 3 and 5 at a pressure of 1000 bars.

\subsection{3. $U S$}

A UP400S Ultrasonic Processor (Hielscher, Teltow, Germany) was used to create nanoemulsions. It is equipped with a $100 \mathrm{~mm}$ titanium cylindrical sonotrode (radius $=7 \mathrm{~mm}$ ) and a sound protection box. Its operating frequency is $24 \mathrm{kHz}$ and its amplitude can be modulated using a simple knob fitted onto the device. To obtain homogeneous size reduction, the emulsion was magnetically stirred throughout the homogenization process. The preparations were placed in an ice bath to limit temperature increase.

Two variables were taken into account when evaluating US as an homogenization method: amplitude which was modulated at $30 \%$ and $60 \%$ and time of exposure which lasted 1, 2 or 5 min. For the stability study, the essay investigated was obtained at $60 \%$ intensity for a duration of 5 min.

\subsection{Particle size distribution measurements}

For droplet size experiments and measurements were all done in triplicate. Average droplet size distributions and average results with standard deviations are presented.

\subsubsection{Dynamic light scattering}

The droplet size was measured by means of dynamic light scattering (DLS) using a Zetasizer Nano Z (Malvern Instruments, France). Data processing of the DLS measurements were done with the Zetasizer software by both cumulants and distribution analysis. Results were Z-average, which is the mean size, and the size distribution in intensity. Before measurement, the nanoemulsions were diluted in ultrapure water (the dilution factor was adjusted to obtain an attenuation factor between 7 and 9). The measurements were realized at $25^{\circ} \mathrm{C}$.

\subsubsection{Laser diffraction}

The droplet sizes of optimized nanoemulsions were measured by Laser Diffraction (LD) particle size analysis with a Mastersizer 3000 (Malvern Instruments, France). The technique is based on measurement 
of the intensity of light scattered as a laser beam passes through a dispersed particulate sample. The Mie scattering theory was used, with a refractive index and an absorption index set at 1.55 and 0.005 for the dispersed phase, respectively. The continuous phase was ultrapure water with a refractive index 1.33. The results were expressed by $D_{50}$ the mean droplet diameter for which $50 \%$ of droplets in volume are below this size and the dispersity of the sample is given by the span value.

\subsection{Optical microscopy}

A Leica DM2000 LED optical microscope fitted with a high definition camera was used to observe droplets without dilution. The images were captured remotely and analyzed via the LAS EZ software developed by Leica. Droplet sizes were determined using the software integrated features.

\subsection{High Performance Liquid Chromatography}

atRA quantification in nanoemulsion was monitored using a RP-HPLC method (Agilent 1200 series) as previously described by Almouazen et al.37]. Briefly, C18 column with $2.6 \mu \mathrm{m}$ particle size (Phenomenex, Kinetex) was used as a stationary phase. Mobile phase composed of 30\% methanol, $35 \%$ acetonitrile, $35 \%$ of deionized water with $0.5 \%$ acetic acid was injected at a flowrate of $1.4 \mathrm{~mL} / \mathrm{min}$. All samples were diluted in acetonitrile and the injected volume was $10 \mu \mathrm{l}$. Finally the UV-detector was used at $\lambda=356 \mathrm{~nm}$.

\subsection{Stability}

Samples of interest were kept in stability in four different conditions: protected from light at temperature of $4^{\circ} \mathrm{C}$, ambient temperature and $40^{\circ} \mathrm{C}$ and exposed to day light at ambient temperature.

\section{Results}

\subsection{Determination of optimal formulation}

$\mathrm{O} / \mathrm{W}$ (oil-in-water) emulsions with HLB values of 9,10 and 11 were observed by optical microscopy and the preparation corresponding to the HLB value of 10 was determined to give the smallest droplet size. The total mass of emulsifier ( $5 \mathrm{~g}$ per $100 \mathrm{~g}$ of emulsion) was comprised of $46 \%$ Tween 20 and $54 \%$ Span 80 , or $2.3 \mathrm{~g}$ and $2.7 \mathrm{~g}$ per $100 \mathrm{~g}$ of emulsion, respectively. The solubility of atRA per gram of MCT was determined to be $2.24 \mathrm{mg}$ in average thus a concentration of $0.02 \%$ was used, $1.88 \%$ of glycerol was added to adjust emulsion osmolality to $0.300 \mathrm{osmol} / \mathrm{kg}$ and be isotonic with plasma.

All experiments were performed at a composition described in Table 1 . The premix was obtained by the same procedure for all experiments as described in Materials and Methods. The droplet size distribution of the premixes were similar for all experiments and determined by LD at $D_{50}=10.3 \mu \mathrm{m}$ and Span $=2.77$.

\subsection{Effect of the process on the resulting droplet size of the nanoemulsions}

Using the predefined premix formulation, nanoemulsions were prepared by the three procedures described in details in Material and Methods. For each procedure, we evaluated and optimized experimental conditions regarding the nanoemusion size distribution determined by DLS. 


\begin{tabular}{|c|c|c|}
\hline \multirow{4}{*}{ Oil } & Component & Mass percentage [\%] \\
\hline \multirow{4}{*}{ Water } & atRA & 0.20 \\
\cline { 2 - 3 } & Span 80 & 2.70 \\
\cline { 2 - 3 } & MCT & 10.00 \\
\hline \multirow{4}{*}{ Wlycerol } & 1.88 \\
\cline { 2 - 3 } & Tween 20 & 2.30 \\
\cline { 2 - 3 } & Water & 82.92 \\
\hline
\end{tabular}

Table 1: Composition of the atRA emulsions formulation

\subsubsection{Effect of PME parameters on resulting droplet size by $D L S$}

In PME, four cycles were performed using decreasing pores sizes. The influence of cycle number on particle size distribution, Z-average and PDI are presented in Figure 2. Considering size distribution presented in Fig $2 \mathrm{a}$, the droplet size was reduced with the number of cycles which is explained by the fact that pore sizes were smaller and smaller after each cycle. All droplets were below $2 \mu \mathrm{m}$ after cycle 1 and 2 , and only cycle 3 and 4 ensured size distribution below $1 \mu \mathrm{m}$. Also, the size distribution width was smaller for cycles 3 and 4 than for cycles 1 and 2 .

Regarding Z-average and PDI (Fig. 2b), which were measured by the same apparatus but estimated by different calculation methods, observations were similar. Z-average decreased from $615 \mathrm{~nm}$ at cycle 1 to 335 $\mathrm{nm}$ at cycle 4. PDI of the nanoemulsions obtained after the first two cycles were slightly above 0.10 , for cycle 1 and 2, 0.10 and 0.13 respectively. For cycle 3 and 4, there were below 0.1: 0.03 and 0.09 respectively. Cycle 1 and 2 produceed quite monodispersed nanoemulsions and cycle 3 and 4 very monodispersed ones. Standard deviations for the different tests and measurements were low from $4 \mathrm{~nm}$ and 0.02 for the last two cycles; to $18 \mathrm{~nm}$ and 0.06 for the first two cycles for Z-average and PDI, respectively.

\subsubsection{Effect of $M F$ parameters on resulting droplet size by $D L S$}

Nanoemulsions were prepared at different pressures; 1000 bars was selected as the optimized one (data

not shown). MF results regarding the influence of cycle number on particle size distribution, Z-average and PDI at a pressure of 1000 bars are presented in Figure 3 Size distributions (Fig. 3a) were significantly different between cycle 1 and all other cycles from 2 to 5 . Indeed, cycle 1 presented a larger distribution and particles above $1 \mu \mathrm{m}$, contrary to all other cycles that showed similar droplet size distributions.

Z-average (Fig. 3b) varied from $162 \mathrm{~nm}$ for cycle 1 to $110 \mathrm{~nm}$ for cycle 5 . Z-average decreased with cycle number, however the decrease from cycle 1 to cycle 2 was the more significant with a value of $38 \mathrm{~nm}$. From 


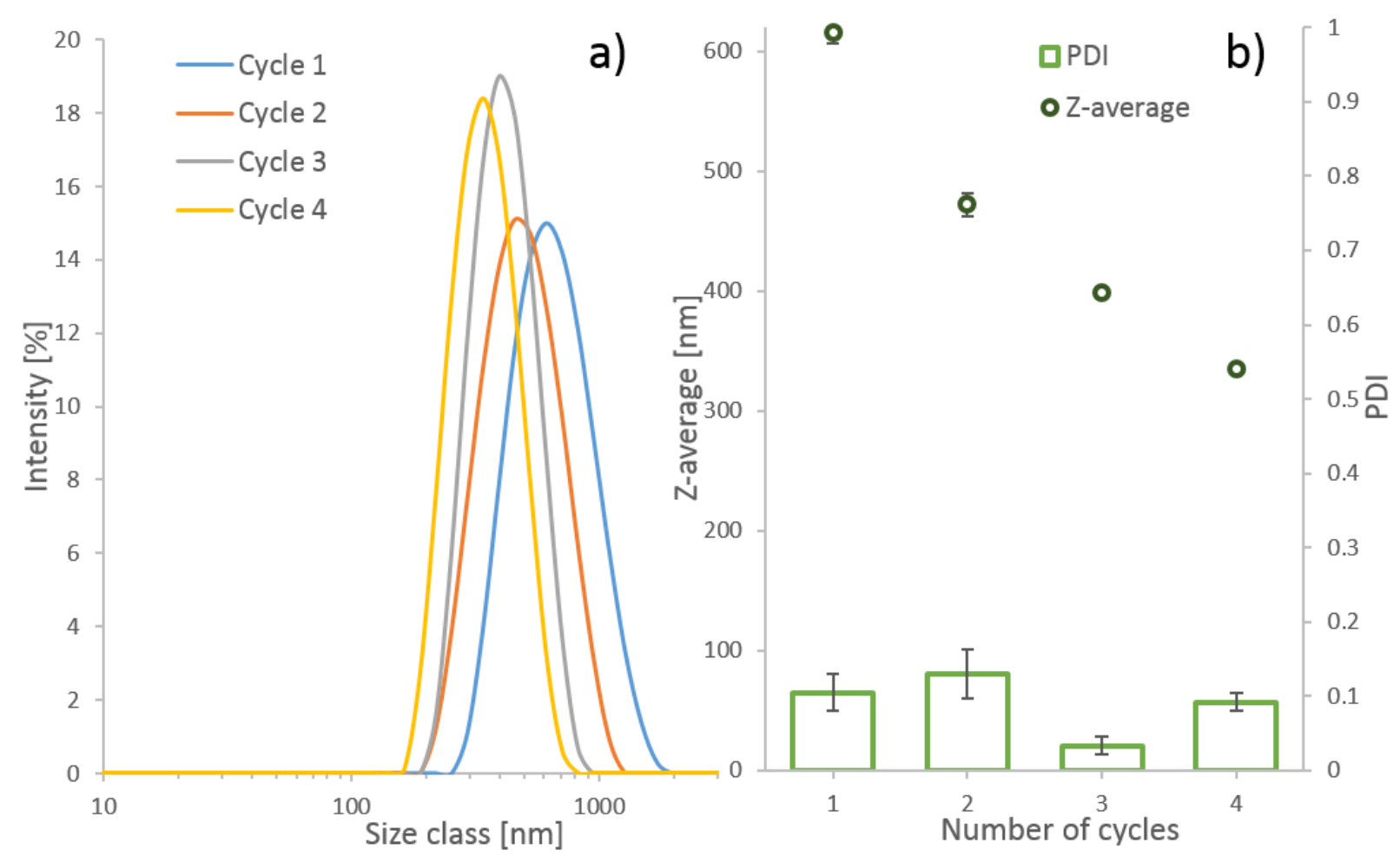

Figure 2: Effect of cycles number on particle size distribution in intensity a); Z-average and PDI b) by DLS for PME at cycles 1 to 4

cycle 2, Z-average values were quite stable. Moreover, standard deviation was high for cycle 1, S.D. $=40$ nm, and negligible for other cycles. PDI values were stable with cycle number and set between 0.11 and 0.17 for cycle 4 and 1 respectively, which indicated quite monodipersed emulsion. As seen on Fig 3 a, size distribution was larger for cycle 1 .

\subsubsection{Effect of US parameters on resulting droplet size by DLS}

Figure 4 presents optimization of droplet sizes of nanoemulsions produced by US. Droplet size distributions at processing time of 1, 2 and $5 \mathrm{~min}$ are shown in Fig $4 \mathrm{a}$ and Z-average and PDI for US intensities of $30 \%$ and $60 \%$ and processing time of 1, 2 and $5 \mathrm{~min}$ in Fig $4 \mathrm{p}$. Regarding droplet size distribution (Fig 4 a), 1 min processing time led to polydispersed and bigger droplets, a part of the distribution being above $1 \mu \mathrm{m}$ compared to longer processing times. At 2 and $5 \mathrm{~min}$, the distributions were similar and all of the distribution was below $1 \mu \mathrm{m}$.

In addition, Z-average (Fig 4 $\mathrm{p}$ ), decreased with processing time, from $334 \mathrm{~nm}$ to $173 \mathrm{~nm}$ at $1 \mathrm{~min}$ and 5 min at 30\% US intensity and from $195 \mathrm{~nm}$ to $173 \mathrm{~nm}$ at $1 \mathrm{~min}$ and $5 \mathrm{~min}$ at $60 \%$ US intensity. Also, at 1 and 2 min processing time, nanoemulsions obtained at $60 \%$ US intensity were smaller than the ones obtained at $30 \%$. However, at $5 \mathrm{~min}$, nanoemulsions obtained at 30\% and 60\% US intensities had the same Z-average. Finally, PDIs, (Fig 4p) were high at 1 min processing time, 0.26 and 0.61 at $30 \%$ US intensity and $60 \%$ US 

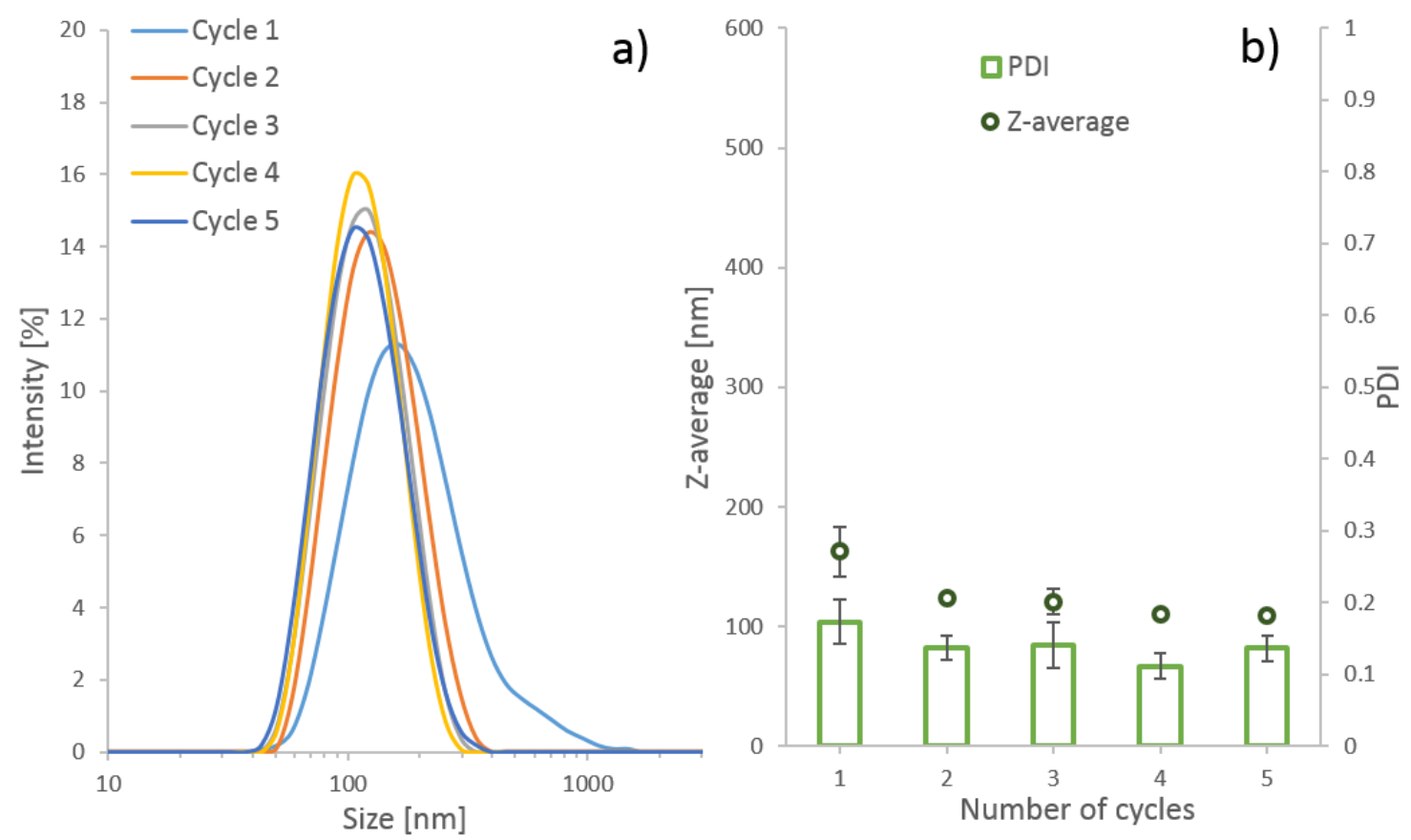

Figure 3: Effect of cycle numbers on particle size distribution in intensity a); Z-average and PDI b) by DLS for MF at a pressure of 1000 bars and cycles 1 to 5

intensity, respectively, with high standard deviation. They both decreased with processing time to finally reached 0.19 and 0.21 at 30\% US intensity and $60 \%$ US intensity, respectively, after 5 min. Even if the PDI values decreased with increasing processing time and US intensity, they were still quite high and DLS may not be the ideal apparatus to measure the mean droplet size, as DLS is aimed at measuring monodispersed emulsions.

\subsubsection{Comparison of the processes regarding droplet size by DLS, LD and optical microscopy}

From previous sections, optimal conditions were determined for each process in order to compare droplets size. For PME, the condition selected was cycle 4, for MF, 1000 bars and cycle 5, for US, 5 min at $60 \%$ US intensity. In this section, only results obtained at these conditions are presented. Size distributions in intensity obtained by DLS and in volume obtained by LD are presented on Figure 4 a) and b) respectively. With DLS (Fig 5 a), the three size distributions were strictly below $1 \mu \mathrm{m}$. PME presented the bigger droplet size but narrower size distribution; US a large size distribution and intermediate mean size; and MF, the smallest size and medium dispersity.

With LD (Fig 5b), the volume size distribution for nanoemulsions prepared by PME was similar to the one obtained by DLS. However, for the two other processes, LD and DLS gave very different size distributions. Indeed, bimodal distributions instead of monomodal were obtained with a first peak between $50 \mathrm{~nm}$ and $300 \mathrm{~nm}$ corresponding to DLS measurements and a second peak between $300 \mathrm{~nm}$ and $1 \mu \mathrm{m}$. Moreover, nanoemulsions produced with US showed two small peaks at around $1.5 \mu \mathrm{m}$ and $2.5 \mu \mathrm{m}$. 

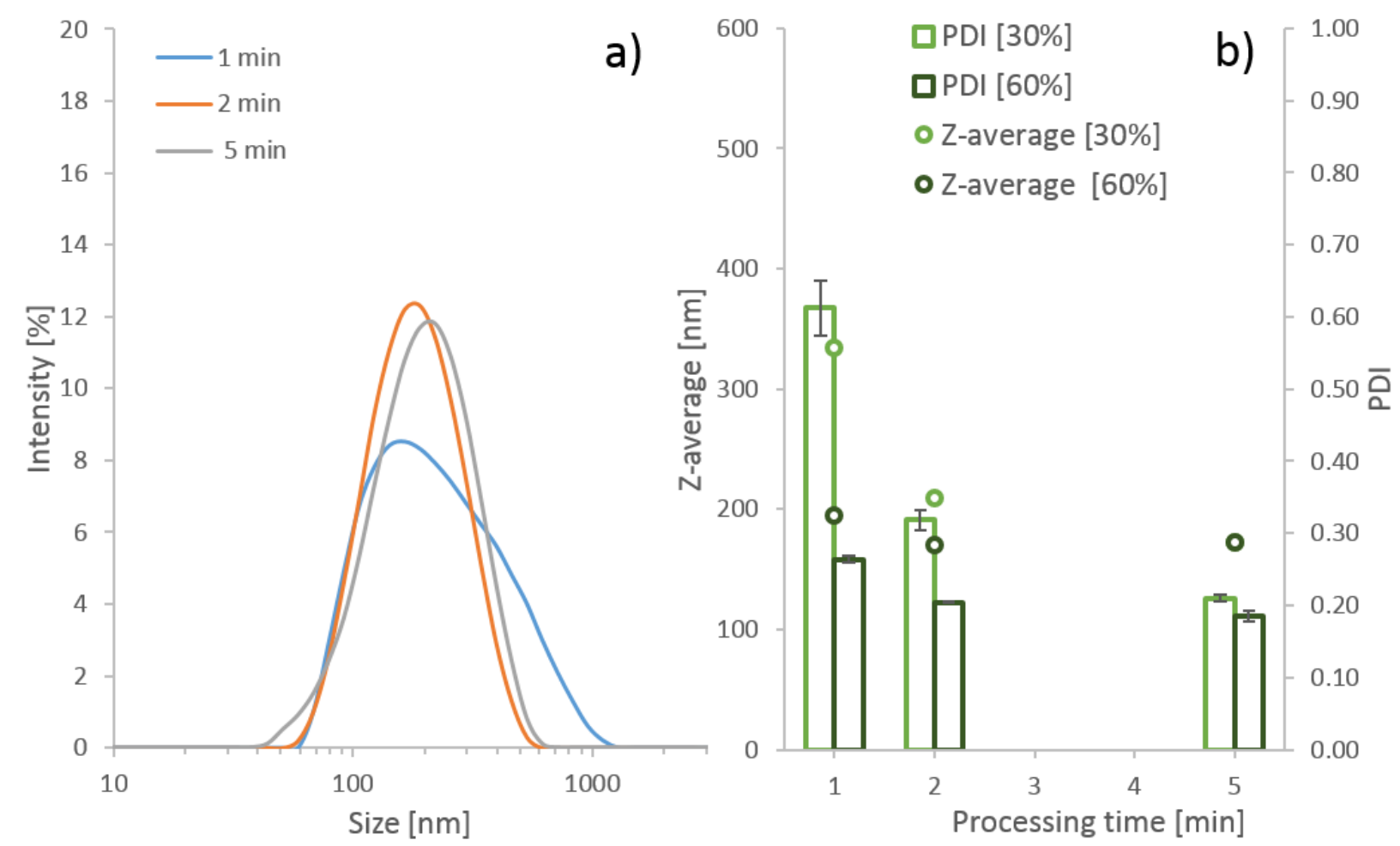

Figure 4: Effect of US duration from 1 min to 5 min on particle size distribution in intensity by DLS a) and effect of US duration and intensity on Z-average and PDI b)

These observations are confirmed by the mean size and dispersity by DLS and LD presented on Table 2 The nanoemulsions obtained by PME presented a mean droplet size value of $335 \mathrm{~nm}$ and $333 \mathrm{~nm}$ by DLS and LD respectively, a PDI of 0.09 and Span of 0.56. This corroborates the results shown on Figure 5 both analytic methods confirmed a monodispersed nanoemulsion with a mean size value of around 330 $\mathrm{nm}$. On the contrary, nanoemulsions obtained by MF presented different mean size and dispersity by DLS and LD. The mean droplet size was $40 \mathrm{~nm}$ bigger with LD than with DLS. But more importantly LD and DLS gave different dispersities. Indeed, nanoemulsion produced by MF presented a Span of 2.75 and could be considered as polydispersed whereas a PDI of 0.14 by DLS indicated a monodispersed sample. Same observation can be made for the nanoemulsions obtained by US, the difference in mean size obtained by DLS and LD was small, $14 \mathrm{~nm}$ smaller by LD, but the dispersities were much different. PDI was measured at 0.19 with DLS, which was considered as quite monodispersed and Span at 2.04 indicating a polydispersed distribution.

A third observation method, optical microscopy, was used to confirm the presence of microscopic droplets $(>1 \mu \mathrm{m})$. On Figure 6 four photographies are presented, two of nanoemulsions obtained with MF at 1000 bars, at cycle 1: Figure 6a) and at cycle 5: Figure 6b). Figure 6c) shows an emulsion produced with US at $60 \%$ intensity during $5 \mathrm{~min}$ and finally Figure 6d) an emulsion produced by PME at cycle 4. On Figure 6a), 


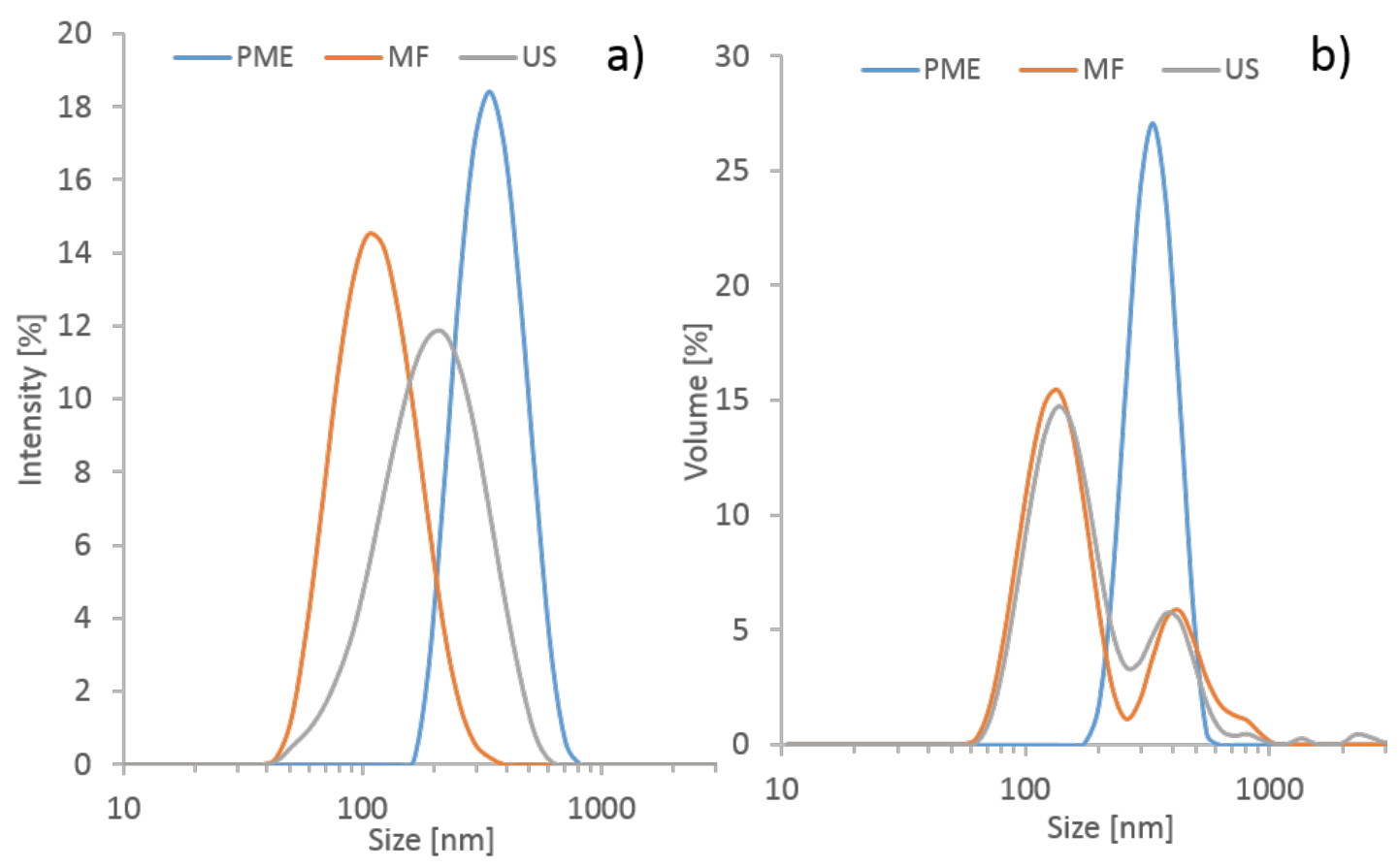

Figure 5: Comparison of size distribution in intensity by DLS a) and in volume by LD b) for the three different processes PME, MF and US for selected conditions

\begin{tabular}{|c|cc|cc|}
\hline & \multicolumn{2}{|c|}{ DLS } & \multicolumn{2}{c|}{ LD } \\
\cline { 2 - 5 } & Z-average & PDI & $D_{50}$ & Span \\
\hline US & $173 \pm 2 \mathrm{~nm}$ & $0.19 \pm 0.01$ & $159 \pm 1 \mathrm{~nm}$ & $2.04 \pm 0.05$ \\
\hline MF & $110 \pm 6 \mathrm{~nm}$ & $0.14 \pm 0.03$ & $152 \pm 4 \mathrm{~nm}$ & $2.75 \pm 0.39$ \\
\hline PME & $335 \pm 4 \mathrm{~nm}$ & $0.09 \pm 0.02$ & $333 \pm 3 \mathrm{~nm}$ & $0.55 \pm 0.04$ \\
\hline
\end{tabular}

Table 2: Summary of size results for the three different processes PME, MF and US for selected conditions

we observe several droplets bigger than $1 \mu \mathrm{m}$ and droplets up to $5.6 \mu \mathrm{m}$ were measured. Figure 6b) shows that most micron size droplets disappeared after 5 cycles but some were still present with size between 1 and $3 \mu \mathrm{m}$, in agreement with what was observed on Figure 5 by LD. Figure 6 ; ) shows the nanoemulsion produced by US, with also micron size droplets. Droplets between 1 and $5 \mu \mathrm{m}$ were observed which is in agreement with the size distribution by LD presented on Figure 5. On the contrary, for nanoemulsions prepared by 
PME (Figure 6d), no droplets can be seen even if the magnificence factor was 100 instead of 40 for the other photographies. This is also in agreement with the droplet size distribution obtained with LD.

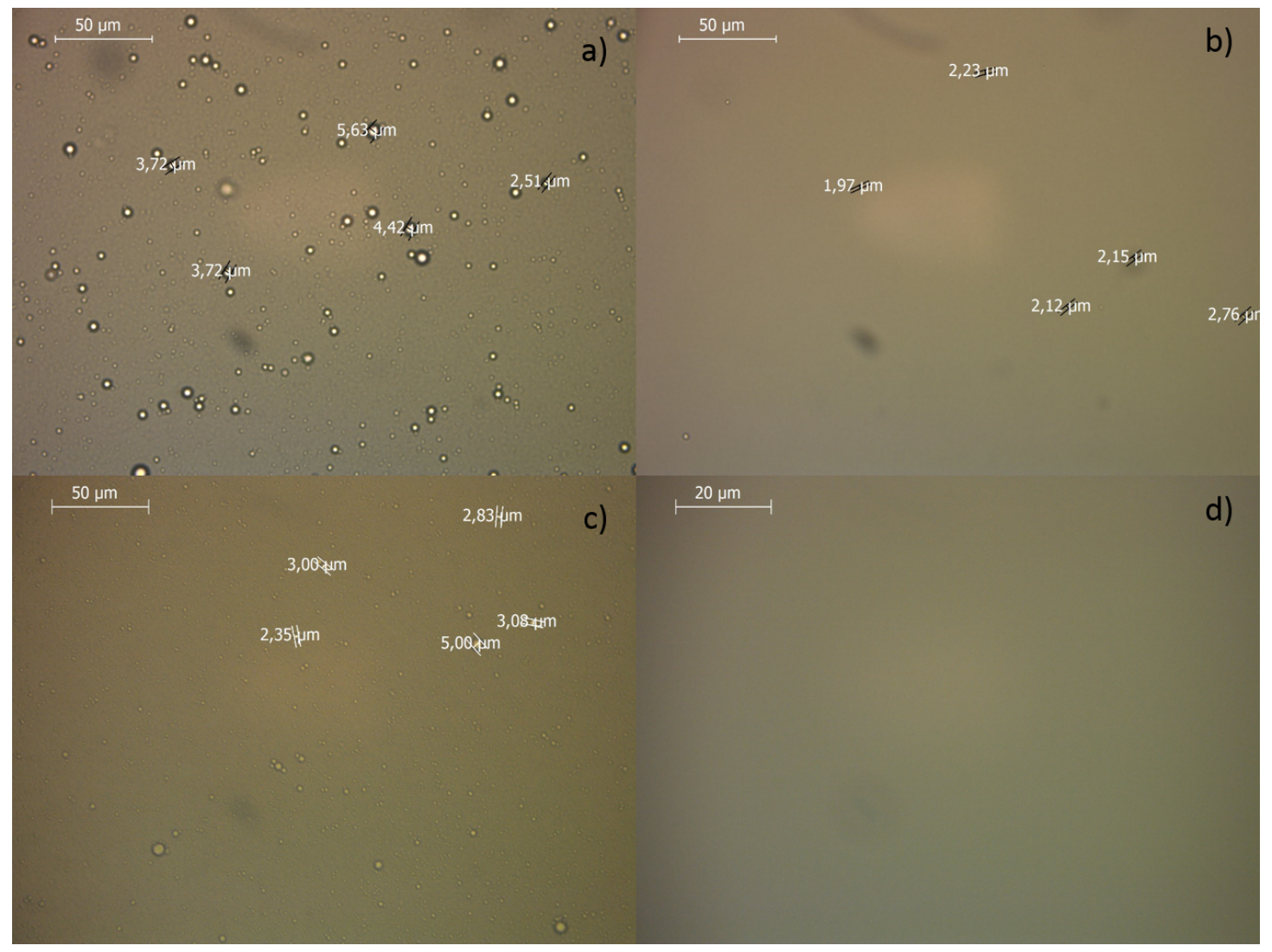

Figure 6: Optical microscopy photographs at x40 of three emulsions a) first cycle of MF at 1000 bars; b) fifth cycle of MF at 1000 bars; c) 5 min at $60 \%$ intensity US; and one at x 100, d) fourth cycle of PME

Stability assessment was made by DLS and presented on Figure 7. Droplet size distributions at each selected condition for each process are presented at $t=0$, just after production, at $t+2$ weeks and at $t+3$ months measured 15 days and 3 months after preparation, respectively, for samples kept at $40^{\circ} \mathrm{C}$. Regarding nanoemulsion produced by PME, a very small difference in droplet size distribution was observed between post production and $\mathrm{t}+3$ months; Z-average values were $335 \mathrm{~nm}$ and $350 \mathrm{~nm}$, respectively. For US, the size distribution changed slightly but not significantly ( $173 \mathrm{~nm}$ at $\mathrm{t}=0$ and $170 \mathrm{~nm}$ at $\mathrm{t}+3$ months). Then for $\mathrm{MF}$, the distribution became larger with Z-average value increased from 110 to $150 \mathrm{~nm}$ at 2 weeks and to $607 \mathrm{~nm}$ at 3 months. For US, the size distribution changed slightly but not significantly. Then for MF, the distribution became larger and mean droplet size increased from 110 to $150 \mathrm{~nm}$ at 2 weeks and to $607 \mathrm{~nm}$ at 3 months. These results were confirmed by LD and optical microscopy (data not shown). 

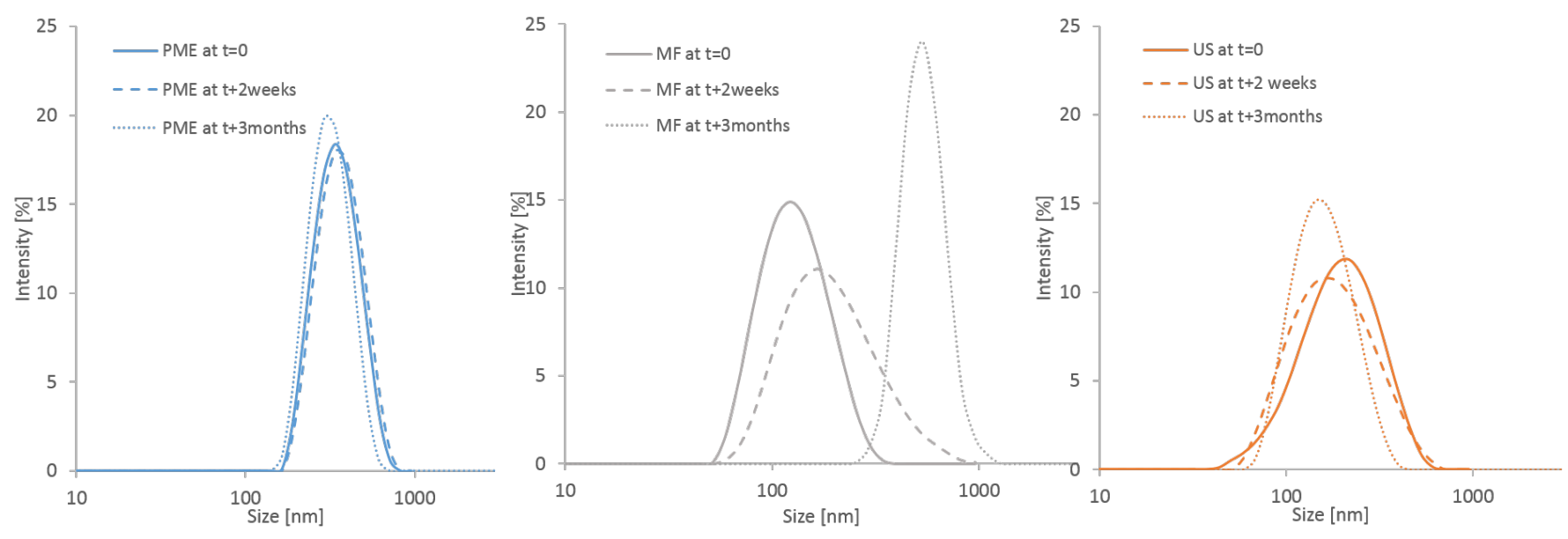

Figure 7: Comparison of size distributions in intensity (DLS) at $t=0, t+2$ weeks and $t+3$ months under accelerated stability at $\left(40^{\circ} \mathrm{C}\right)$ for nanoemulsions prepared by PME, MF and US with selected conditions

\subsection{Effect of the process on API degradation}

Results presented in this section were obtained at the optimal conditions determined previously for each

process. AtRA degradation was negligible for each process and approximately $100 \%$ of atRA was recovered at the end of the production (data not shown). AtRA stability was investigated under accelerated and normal stability conditions including light and temperature over 2 weeks (Figure 8).

The stability conditions investigated were ambient temperature in day light and protected from day light, at $4^{\circ} \mathrm{C}$ protected from day light and at $40^{\circ} \mathrm{C}$ protected from day light. At $4^{\circ} \mathrm{C}$, no degradation of atRA occurred regardless of the process used, the lowest percentage being $97 \%$ after 2 weeks for PME and MF. At ambient temperature, in dark conditions, degradation started slowly with the lowest percentage of $84 \%$ obtained for MF. No real difference was seen between the different processes. To evaluate the process impact on atRA degradation and predict long term stability, stressed stability at $40^{\circ} \mathrm{C}$ was done over 2 weeks. After 1 week, MF showed the lowest percentage at 18\% followed by PME at $67 \%$ and finally US seemed to present no degradation but a very high standard deviation compared to the other processes. At 2 weeks, atRA completely disappeared for MF whereas for PME and US it was still present at 35\% and 54\%, respectively. The chromatography analysis showed a decrease of atRA within the nanoemulsion without any isomeration as the principal isomers $(13 \mathrm{cis}, 9 \mathrm{cis}$ and $11 \mathrm{cis}$ ) were not detected (Figure 9). In order to study the process impact on atRA isomeration, stability under day light exposure was also performed over 2 weeks. After one week, like with other conditions, MF was the most degraded down to $21 \%$, followed by PME, $35 \%$ and finally US with $41 \%$. After two weeks the percentages became very low: $17 \%$ for MF, $22 \%$ for PME and $25 \%$ for US. This reduced atRA quantity under light was mainly due to isomeration as the three isomers can be seen, peaks at $15.5 \mathrm{~min}$ for 9-cis-atRA, at $14 \mathrm{~min}$ for 13-cis-atRA and at 12.5 for 11-cis-atRA by chromatography analysis (Figure 9) and no difference was observed between the three processes.

These data were completed by long term stability measurements at 3 months at $4^{\circ} \mathrm{C}$ and percentage were 
found to be $77 \%, 76 \%$ and $63 \%$ for nanoemulsions produced by US, PME and MF respectively (data not shown), which is in accordance with accelerated stability.

Overall, the process which seems to degrade less atRA was US, followed closely by PME but nanoemulsions produced by MF were significantly more degraded at the more extreme conditions regarding temperature and light exposure.
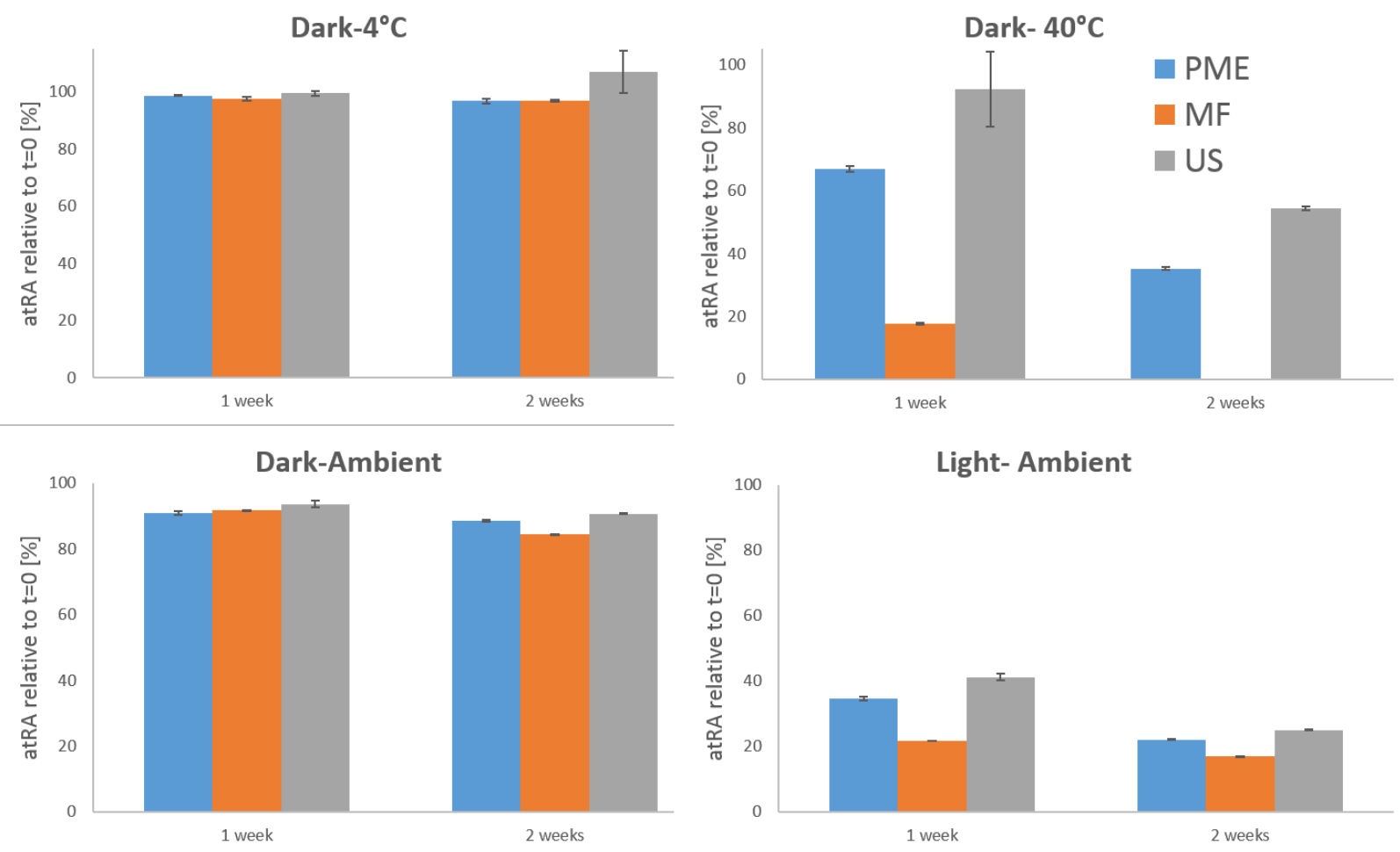

Figure 8: Stability of atRA nanoemulsions during 2 weeks: remained atRA was determined and expressed as percentage of post-production content

\section{Discussion}

Emulsions produced by US and MF at optimal conditions presented similar characteristics, with very fine droplets below $200 \mathrm{~nm}$ but large size distribution. This large size distribution was not seen by DLS which is not adapted to polydispersed samples. However, it was observed by two other techniques, LD and optical microscopy. US is known to produce polydispersed samples as only the suspension near the sonifier probe is affected by ultrasonic waves [38. In MF, all droplets need to experience the peak shear rate generated by a flow-producing device otherwise the resulting emulsions are polydispersed 39. This explains why several cycles are needed, and this study shows that even after 5 cycles, micron size droplets were present in the sample. PME presented a different droplet size distribution profile, the optimized sample had a mean value of $335 \mathrm{~nm}$ and a good monodispersity confirmed by DLS, LD and optical microscopy showing no micron sized 

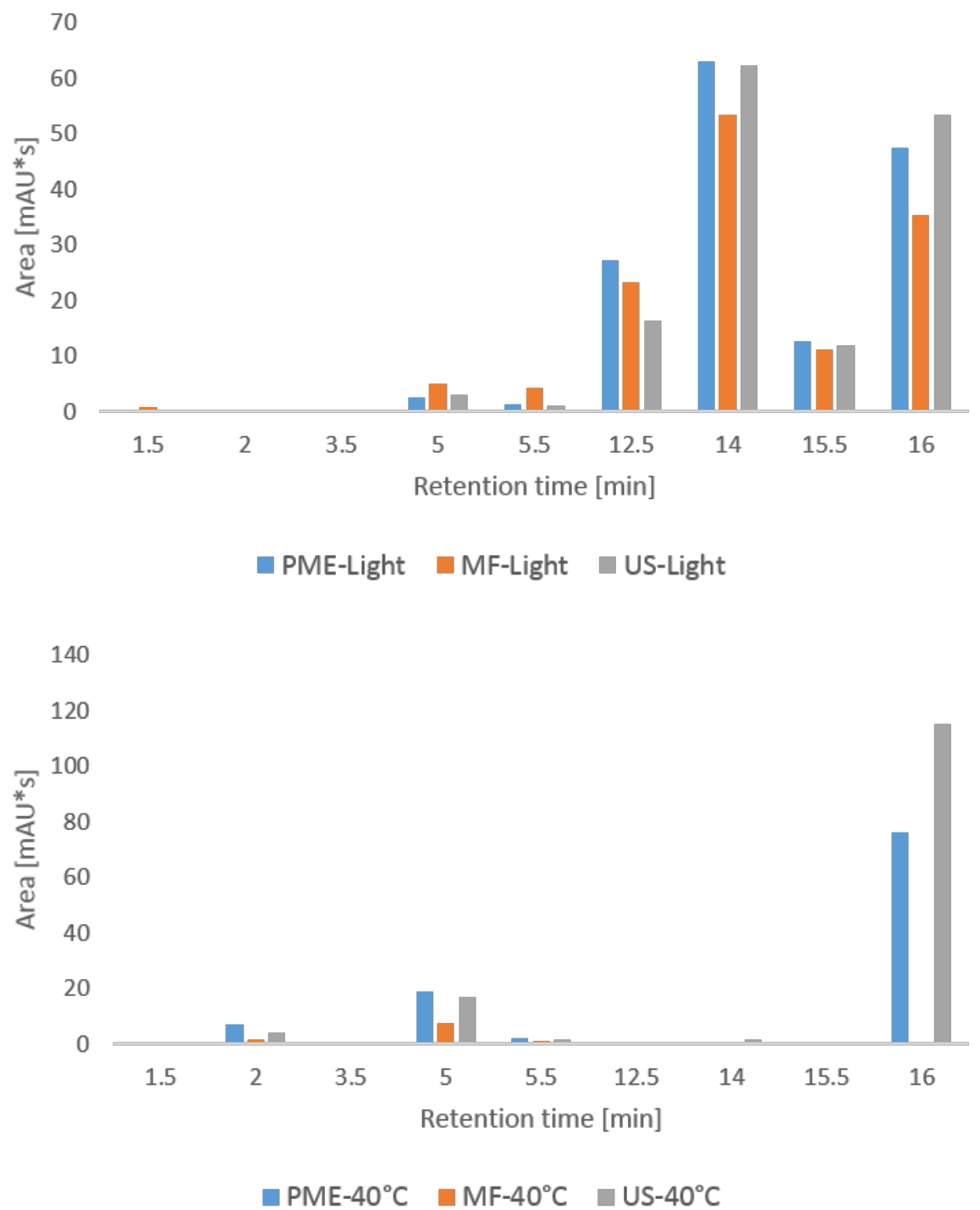

Figure 9: Peak areas at different retention times after 2 weeks in stability at day light exposure and $40^{\circ} \mathrm{C}$

droplets. These results were similar to the ones obtained previously with this set-up and the same surfactant system [22].

In terms of stability, nanoemulsions produced by PME and US did not present any destabilization over 3 months under stressed stability at $40^{\circ} \mathrm{C}$. On the contrary, MF showed emulsion droplets $36 \%$ bigger after 2 weeks and $452 \%$ after 3 months. These nanoemulsions can be considered unstable.

The three processes produced nanoemulsions that can be used in intravenous applications. However, MF and US will loose expensive active ingredients during the filtration/sterilization step where micron droplets will be removed. On the contrary, a sterile nanoemulsion can be obtained by PME, if the membrane is sterilized as the final pore size used is $0.2 \mu \mathrm{m}$ [21. Thus PME could be a one step process of emulsifica- 

all low PDI and a mean droplet size below $200 \mathrm{~nm}$ by DLS. However, by LD and optical microscopy, bigger droplets above $500 \mathrm{~nm}$ and a very large dispersity were measured. By US, after 5 min, all nanoemulsions were below $200 \mathrm{~nm}$ but with quite high PDI. By LD and optical microscopy, some bigger droplets were seen above 
$1 \mu \mathrm{m}$. Moreover, nanoemulsions produced by US appeared to be more polydispersed. In stressed stability, nanoemulsions produced by US and PME did not change over 3 months. Those produced by MF, on the contrary showed a drastic increase in droplet size of $426 \%$ after 3 months. Nanoemulsions produced by MF were found unstable under stress conditions.

Also, the three processes were evaluated for their impact on drug degradation and no difference was seen.

In stability, no significant difference was observed of atRA degradation at $t=0$ and after 2 weeks of storage at $4^{\circ} \mathrm{C}$ and dark ambient temperature. However, atRA nanoemulsion exposed to $40^{\circ} \mathrm{C}$ or day light showed rapid atRA degradation with significant differences between the three processes. Nanoemulsions prepared by US showed the best overall resistance to degradation, followed by the one produced by PME and finally by $\mathrm{MF}$ which was totally degradated after 2 weeks at $40^{\circ} \mathrm{C}$ and showed the higher degradation under light exposure.

In conclusion, all processes are suitable to produce injectable nanoemulsions but only PME was adapted to thermosensitive actives with the potential of large scale production. Moreover, in terms of droplet size, PME produced monodispersed droplets of $330 \mathrm{~nm}$ compared to the other processes which produced nanoemulsions of around $150 \mathrm{~nm}$ but with the presence of micron size droplets combined with droplet instability over 3 months for MF. Therefore, PME could be an alternative industrial process for parenteral emulsions manufacturing with no additional sterilization step and a lower energy requirement. Nanoemulsions were found unstable under stress conditions; that can be explained by more severe processing conditions that create droplets friction and other physical stresses and thus less stable emulsions.

\section{Acknowledgment}

This work was supported by PeptiCaps project. This project has received funding from the European Union's Horizon 2020 Research and Innovation program under Grant Agreement nº686141.

\section{References}

[1] C. Lovelyn, A. A. Attama, Current State of Nanoemulsions in Drug Delivery, Journal of Biomaterials and Nanobiotechnology 02 (05) (2011) 626-639. doi:10.4236/jbnb.2011.225075.

\section{URL http://www.scirp.org/journal/doi .aspx?DOI=10.4236/jbnb.2011.225075}

[2] D. Mou, H. Chen, D. Du, C. Mao, J. Wan, H. Xu, X. Yang, Hydrogel-thickened nanoemulsion system for topical delivery of lipophilic drugs, International Journal of Pharmaceutics 353 (1-2) (2008) 270-276.

[3] S. Setya, S. Talegaonkar, B. K. Razdan, Nanoemulsions: formulation methods and stability aspects, World Journal of Pharmaceutical Sciences 3 (2) (2014) 2214-2228.

[4] A. G. Floyd, Top ten considerations in the development of parenteral emulsions, Pharmaceutical Science \& Technology Today 2 (4) (1999) 134-143. 
口 [5] X. Yang, D. Wang, Y. Ma, Q. Zhao, J. K. Fallon, D. Liu, X. E. Xu, Y. Wang, Z. He, F. Liu, Theranostic nanoemulsions: codelivery of hydrophobic drug and hydrophilic imaging probe for cancer therapy and imaging, Nanomedicine 9 (18) (2014) 2773-2785, pMID: 25000945. arXiv:https://doi.org/10.2217/ nnm.14.50, doi:10.2217/nnm.14.50.

URL https://doi .org/10.2217/nnm.14.50

[ [6] A. Desai, T. Vyas, M. Amiji, Cytotoxicity and apoptosis enhancement in brain tumor cells upon coadministration of paclitaxel and ceramide in nanoemulsion formulations, Journal of Pharmaceutical Sciences 97 (7) (2008) 2745 - 2756. doi:https://doi.org/10.1002/jps.21182.

405 URL http://wWw.sciencedirect.com/science/article/pii/S0022354916326284

q [7] I. Venkateshwarlu, K. Prabhakar, M. Ali, V. Kishan, Development and in vitro cytotoxic evaluation of parenteral docetaxel lipid nanoemulsions for application in cancer treatment, PDA Journal of Pharmaceutical Science and Technology 64 (3) (2010) 233-241, cited By 8. URL https://www. scopus.com/inward/record. uri?eid=2-s2.0-78149352110\&partnerID=40\&md5= 7d51fef7a38566d82248c4ab44bbc281

[ [8] K. K. Singh, S. K. Vingkar, Formulation, antimalarial activity and biodistribution of oral lipid naघ noemulsion of primaquine, International Journal of Pharmaceutics 347 (1) (2008) 136 - 143. doi: https://doi.org/10.1016/j.ijpharm.2007.06.035.

URL http://www.sciencedirect.com/science/article/pii/S0378517307005522

[9] ClinicalTrials.gov Bethesda (md): National Library of Medicine (US). February 29, 2000 . Identifier NCT01326078. Use of Lipid Emulsion or Nanoemulsion of Propofol on Children Undergoing Ambulatory Invasive Procedures, March 30, 2011; Available at: https://clinicaltrials.gov/ct2/show/nct01326078. Accessed September 26, 2018.

[10] ClinicalTrials.gov Bethesda (md): National Library of Medicine (US). February 29, 2000 . Identifier NCT01010035. Cholesterol Metabolism and Lipid Transfer in Diabetes; Nov 9, 2009 Available at: https://clinicaltrials.gov/ct2/show/nct01010035. Accessed September 26, 2018.

[11] C. Solans, I. Solé, Nano-emulsions: Formation by low-energy methods, Current Opinion in Colloid \& Interface Science 17 (5) (2012) 246-254. doi:10.1016/j.cocis.2012.07.003.

URL http://linkinghub.elsevier.com/retrieve/pii/S1359029412000787

${ }_{425}^{4}[12]$ M. N. Yukuyama, D. D. M. Ghisleni, T. J. A. Pinto, N. A. Bou-Chacra, Nanoemulsion: process selection 口 and application in cosmetics - a review, International Journal of Cosmetic Science (2015) n/a-n/adoi: $10.1111 /$ ics. 12260

URL http://doi.wiley.com/10.1111/ics.12260 
[13] S. Schultz, G. Wagner, K. Urban, J. Ulrich, High-pressure homogenization as a process for emulsion formation, Chemical Engineering \& Technology 27 (4) (2004) 361-368. doi:10.1002/ceat.200406111. URL http://doi.wiley.com/10.1002/ceat.200406111

[14] T. Tadros, P. Izquierdo, J. Esquena, C. Solans, Formation and stability of nano-emulsions, Advances in Colloid and Interface Science 108-109 (2004) 303-318. doi:10.1016/j.cis.2003.10.023. URL http://linkinghub.elsevier.com/retrieve/pii/S000186860300157X

[15] Y. Singh, J. G. Meher, K. Raval, F. A. Khan, M. Chaurasia, N. K. Jain, M. K. Chourasia, Nanoemulsion: Concepts, development and applications in drug delivery, Journal of Controlled Release 252 (2017) 2849. doi:10.1016/j.jconrel.2017.03.008. URL https://linkinghub.elsevier.com/retrieve/pii/S0168365917301128

[16] A. Nazir, K. Schroën, R. Boom, Premix emulsification: A review, Journal of Membrane Science 362 (1-2) (2010) 1-11. doi:10.1016/j.memsci.2010.06.044.

URL http://linkinghub.elsevier.com/retrieve/pii/S0376738810005119

[17] G. Vladisavljević, M. Shimizu, T. Nakashima, Preparation of monodisperse multiple emulsions at high production rates by multi-stage premix membrane emulsification, Journal of Membrane Science 244 (1-2) (2004) 97-106. doi:10.1016/j.memsci.2004.07.008.

[18] S. Gehrmann, H. Bunjes, Instrumented small scale extruder to investigate the influence of process parameters during premix membrane emulsification, Chemical Engineering Journal 284 (2016) 716-723. doi:10.1016/j.cej.2015.09.022.

URL http://linkinghub.elsevier . com/retrieve/pii/S1385894715012796

450 [19] S. Joseph, H. Bunjes, Evaluation of Shirasu Porous Glass (SPG) membrane emulsification for the preparation of colloidal lipid drug carrier dispersions, European Journal of Pharmaceutics and Biopharmaceutics 87 (1) (2014) 178-186. doi:10.1016/j.ejpb.2013.11.010. URL http://linkinghub.elsevier.com/retrieve/pii/S0939641113003822

[20] S. Gehrmann, H. Bunjes, Preparation of lipid nanoemulsions by premix membrane emulsification with disposable materials, International Journal of Pharmaceutics 511 (2) (2016) 741-744. doi:10.1016/j. ijpharm.2016.07.067.

URL http://linkinghub.elsevier.com/retrieve/pii/S0378517316307177

[21] S. Joseph, H. Bunjes, Preparation of nanoemulsions and solid lipid nanoparticles by premix membrane emulsification, Journal of Pharmaceutical Sciences 101 (7) (2012) 2479-2489. doi:10.1002/jps.23163. URL http://doi.wiley.com/10.1002/jps.23163 
[22] O. Alliod, J.-P. Valour, S. Urbaniak, H. Fessi, D. Dupin, C. Charcosset, Preparation of oil-in-water nanoemulsions at large-scale using premix membrane emulsification and Shirasu Porous Glass (SPG) mem-

- branes, Colloids and Surfaces A: Physicochemical and Engineering Aspectsdoi:10.1016/j.colsurfa. 2018.04 .045 .

URL http://linkinghub.elsevier.com/retrieve/pii/S0927775718303212

[23] G. T. Vladisavljević, U. Lambrich, M. Nakajima, H. Schubert, Production of O/W emulsions using SPG membranes, ceramic $\alpha$-aluminium oxide membranes, microfluidizer and a silicon microchannel platea comparative study, Colloids and Surfaces A: Physicochemical and Engineering Aspects 232 (2-3) (2004) 199-207. doi:10.1016/j.colsurfa.2003.10.026

[24] S. Mahdi Jafari, Y. He, B. Bhandari, Nano-Emulsion Production by Sonication and Microfluidizaa tion - A Comparison International Journal of Food Properties 9 (3) (2006) 475-485. doi:10.1080/ 10942910600596464

URL http://www.tandfonline.com/doi/abs/10.1080/10942910600596464

475 [25] S. Y. Tang, P. Shridharan, M. Sivakumar, Impact of process parameters in the generation of novel aspirin nanoemulsions comparative studies between ultrasound cavitation and microfluidizer, Ultrasonics Sonochemistry 20 (1) (2013) 485 - 497. doi:https://doi.org/10.1016/j.ultsonch.2012.04.005. URL http://www.sciencedirect.com/science/article/pii/S1350417712000806

[26] E. Trapasso, D. Cosco, C. Celia, M. Fresta, D. Paolino, Retinoids: new use by innovative drug-delivery systems, Expert Opinion on Drug Delivery 6 (5) (2009) 465-483. doi:10.1517/17425240902832827 URL http://www.tandfonline.com/doi/full/10.1517/17425240902832827

[27] M. Huang, Y.-C. Ye, S. Chen, J.-R. Chai, J.-X. Lu, L. Zhoa, L. Gu, Z.-Y. Wang, Use of all-trans retinoic acid in the treatment of acute promyelocytic leukemia, Blood 72 (2) (1988) 567-572.

[28] S. Castaigne, C. Chomienne, M. T. Daniel, P. Ballerini, R. Berger, P. Fenaux, L. Degos, All-trans retinoic acid as a differentiation therapy for acute promyelocytic leukemia. I. Clinical results, Blood 76 (9) (1990) 1704-1709.

[29] D. K. Singh, S. M. Lippman, Cancer Chemoprevention-Part 1: Retinoids and Carotenoids and Other Classic Antioxidants, Physicians Practice 12 (1998) 1643-1658.

[30] M. Bryan, E. D. Pulte, K. C. Toomey, L. Pliner, A. C. Pavlick, T. Saunders, R. Wieder, A pilot phase II 490 trial of all-trans retinoic acid (Vesanoid) and paclitaxel (Taxol) in patients with recurrent or metastatic breast cancer, Investigational New Drugs 29 (6) (2011) 1482-1487. doi:10.1007/s10637-010-9478-3. URL http://link.springer.com/10.1007/s10637-010-9478-3 
[31] L. Coelho, I. Almeida, J. Sousa Lobo, J. Sousa e Silva, Photostabilization strategies of photosensitive drugs, International Journal of Pharmaceutics 541 (1-2) (2018) 19-25. doi:10.1016/j.ijpharm.2018. 02.012

URL https://linkinghub.elsevier.com/retrieve/pii/S0378517318300930

[32] B. Ozpolat, G. Lopez-Berestein, P. Adamson, C. J. Fu, A. H. Williams, Pharmacokinetics of intravenously administered liposomal all-trans-retinoic acid (ATRA) and orally administered ATRA in healthy volunteers, Journal of Pharmacy and Pharmaceutical Sciences 6 (2) (2003) 292-301.

[33] A. Ourique, S. Azoubel, C. Ferreira, C. Silva, M. Marchiori, A. Pohlmann, S. S. Guterres, R. Beck, Lipid-core nanocapsules as a nanomedicine for parenteral administration of tretinoin: development and in vitro antitumor activity on human myeloid leukaemia cells, Journal of Biomedical Nanotechnology 6 (3) (2010) 214-223.

[34] A. Chinsriwongkul, P. Chareanputtakhun, T. Ngawhirunpat, T. Rojanarata, W. Sila-on, U. Ruktanonchai, P. Opanasopit, Nanostructured Lipid Carriers (NLC) for Parenteral Delivery of an Anticancer Drug, AAPS PharmSciTech 13 (1) (2012) 150-158. doi:10.1208/s12249-011-9733-8

URL http://www . springerlink.com/index/10.1208/s12249-011-9733-8

[35] E. Schultze, J. Buss, K. Coradini, K. R. Begnini, S. S. Guterres, T. Collares, R. C. R. Beck, A. R. Pohlmann, F. K. Seixas, Tretinoin-loaded lipid-core nanocapsules overcome the triple-negative breast $510 \quad$ cancer cell resistance to tretinoin and show synergistic effect on cytotoxicity induced by doxorubicin and ․ 5-fluororacil, Biomedicine \& Pharmacotherapy 96 (2017) 404-409. doi:10.1016/j.biopha.2017.10. 020 .

URL https://linkinghub.elsevier.com/retrieve/pii/S0753332217330925

[36] S. H. Silalahi, T. Leiknes, Cleaning strategies in ceramic microfiltration membranes fouled by oil and particulate matter in produced water, Desalination 236 (1-3) (2009) 160-169. doi:10.1016/j.desal. 2007.10 .063

URL http://linkinghub.elsevier.com/retrieve/pii/S0011916408006395

[37] E. Almouazen, S. Bourgeois, A. Boussad, P. Valot, C. Malleval, H. Fessi, S. Nataf, S. Brianon, Development of a nanoparticle-based system for the delivery of retinoic acid into macrophages, International Journal of Pharmaceutics 430 (1) (2012) 207 - 215. doi:https://doi.org/10.1016/j.ijpharm.2012. 03.025 .

URL http://www .sciencedirect.com/science/article/pii/S0378517312002669

[38] N. Anton, J.-P. Benoit, P. Saulnier, Design and production of nanoparticles formulated from nano口 emulsion templates-a review, Journal of Controlled Release 128 (3) (2008) 185 - 199. doi:https: ${ }_{525} \quad / /$ doi.org/10.1016/j.jconrel.2008.02.007. URL http://www.sciencedirect.com/science/article/pii/S0168365908001016 
[39] M. M. Fryd, T. G. Mason, Advanced nanoemulsions, Annual Review of Physical Chemistry 63 (1) (2012) 493-518, pMID: 22475339. arXiv:https://doi.org/10.1146/annurev-physchem-032210-103436, doi:10.1146/annurev-physchem-032210-103436. URL https://doi.org/10.1146/annurev-physchem-032210-103436

[40] S.-J. Lim, M.-K. Lee, C.-K. Kim, Altered chemical and biological activities of all-trans retinoic acid incorporated in solid lipid nanoparticle powders, Journal of Controlled Release 100 (1) (2004) 53 - 61. doi:https://doi.org/10.1016/j.jconrel.2004.07.032.

URL http://www.sciencedirect.com/science/article/pii/S0168365904003773

[41] W. Li, T. S. H. Leong, M. Ashokkumar, G. J. O. Martin, A study of the effectiveness and energy 口 efficiency of ultrasonic emulsification, Physical Chemistry Chemical Physics 20 (1) (2018) 86-96. doi: 10.1039/C7CP07133G.

URL http://xlink.rsc.org/?DOI=C7CP07133G 